Lauren Scharff, UNITED STATES AIR FORCE ACADEMY, lauren.scharff@usafa.edu John Draeger, SUNY BUFFALO STATE, draegejd@buffalostate.edu Dominique Verpoorten, IFRES-UNIVERSITY OF LIÈGE, sergentvitamine@gmail.com Marie Devlin, NEWCASTLE UNIVERSITY, marie.devlin@newcastle.ac.uk Lucie S. Dvorakova, UNIVERSITY OF QUEENSLAND, lucie.n.dvorakova@gmail.com Jason M. Lodge, UNIVERSITY OF MELBOURNE, jason.lodge@unimelb.edu.au Susan Smith, LEEDS BECKETT UNIVERSITY, s.v.smith@leedsbeckett.ac.uk

\title{
Exploring Metacognition as Support for Learning Transfer
}

\section{ABSTRACT}

The ability to transfer learning to new situations lies at the heart of lifelong learning and the employability of university graduates. Because students are often unaware of the importance of learning transfer and staff do not always explicitly articulate this expectation, this article explores the idea that metacognition (intentional awareness and the use of that awareness) might enhance the development of learning transfer. Our exploratory study includes results from a survey of 74 staff and 118 students from five institutions in Australia, Belgium, UK, and USA. Our data indicate that many staff and a majority of students do not have a clear understanding of what learning transfer entails, and that there are many mismatches between staff and student perceptions, attitudes, and behaviors regarding learning transfer. This helps explain why learning transfer does not occur as often as it could. We found significant positive correlations between thinking about transfer and thinking about learning processes and the likelihood to use awareness of metacognition to guide practice. Our findings suggest a positive relationship between metacognition and learning transfer. Implications for the scholarship of teaching and learning are discussed.

\section{KEYWORDS}

learning transfer, metacognition, student perspectives, faculty perspectives

\section{INTRODUCTION}

The ability to adapt learning to new contexts is one skill many industries report wanting in their employees (Muhamad, 2012) and one at the heart of lifelong learning (Cronon, 1998). The scholarship of teaching and learning (SoTL) offers ongoing and systematic investigations into student learning. SoTL scholars have argued for the importance of applying learning to new contexts (Huber \& Hutchings, 2004) and examined techniques for facilitating self-directed learning transfer (Douglass \& Morris, 2014).

This article explores the idea that metacognition might enhance learning transfer and its development. It includes pilot survey data from students and staff regarding their beliefs and behaviors. 'Learning transfer' refers to the ability to take what is learned in one context and apply it effectively in another. For example, learning transfer can occur across assignments within a course, across a program of study, into an employment situation, and across someone's personal life. In some cases, the similarity 
between contexts might be obvious, and transfer will be easier. In most cases, a mix of prior knowledge and skills will be needed in the new situation, which might occur after some gap in time. Such transfer can be more difficult. Successful navigation of less obvious transfer situations will require awareness of the similarities and the differences in context, of one's skills, and of the knowledge that might be appropriate in the new context. As choices about whether and how to transfer skills or knowledge are made, one should monitor success and make thoughtful modifications as needed.

We define 'metacognition' as this intertwining of awareness (i.e., self-monitoring) and use of that awareness (i.e., self-regulation) to advance a process (e.g., writing, studying, learning transfer, driving, cooking). We argue that metacognition can support learning transfer, and that an investigation of the connection between learning transfer and metacognition will help address the goals of lifelong learning and employability.

\section{Challenges for the development of learning transfer}

Despite its foundational importance in higher education, the goal of developing learning transfer capacity is often unmet. First, students often do not know learning transfer is expected (Lightner, Benander, \& Kramer, 2008), though there are several channels through which students can acquire knowledge about its significance (e.g., instructors, textbooks, peers). Second, even for students aware of its importance, learning transfer can be difficult because they are not always aware of transfer strategies, especially when transferring to 'real world experience' (Billing, 2007). Third, students do not always know the material well enough to make the necessary connections (Lightner, et al., 2008). For example, students may have an excellent surface understanding of concepts, but this can break down when asked to make deep connections (Newman, Catavero, \& Wright, 2012). Fourth, instructors don't always teach in ways that support learning transfer (Benander \& Lightner, 2005). For example, if graded assignments and class time do not explicitly demand students practice making connections, then students may not fully appreciate the value of learning transfer or know how it is done.

Taken together, the above reasons suggest that there is a lack of explicit communication about the importance of learning transfer and there is need to develop explicit strategies for learning transfer. However, obstacles may persist even when instructors explicitly ask students to make connections (Nowacek, 2011). For example, instructors can inadvertently discourage some forms of learning transfer while trying to encourage others (e.g., instructors hoping for content applications from one disciplinary context to another might not recognize or reward students applying disciplinary insights to their personal lives), and instructors can work at cross purposes (e.g., when one instructor's preferred method of writing an essay differs, or even conflicts with, another instructor's method). Further, if students don't have available strategies to support learning transfer, they may inappropriately apply whatever skill or knowledge most readily available in their personal repertoire (e.g., prior knowledge, skills, life experiences). Even if they succeed, students may be unable to clearly articulate how or why they succeeded, so they cannot be sure they can successfully do it again. We believe that making the transfer process an object of metacognition will encourage students and staff to intentionally develop and incorporate transfer strategies, monitor whether the strategies are effective, and use that awareness to make adaptive changes when appropriate.

\section{Some ways metacognition supports transfer}

Metacognition and learning transfer have been studied for decades, generally as independent constructs, by a large number of investigators. Prior research suggests metacognition is akin to constructs like learning to learn (Hoskins \& Fredriksson, 2008), learning about learning (Watkins, 
2001), learning skills (Higgins, Baumfield, \& Hall, 2007), reflective practice (Moon, 2001), selfregulated learning (Isaacson \& Fujita, 2006) and situational awareness (Salomon \& Perkins, 2007). Metacognition has been shown to facilitate many learning processes, including the ability to manage complex tasks (Veenman \& Beishuizen, 2004) and learning involving emotionally-charged subjects (Chick, Karis, \& Kernahan, 2009). Metacognition can also support improved learning efficiency (Case \& Gunstone, 2002).

A few investigators have briefly acknowledged metacognition might serve as a route to transfer (e.g., Benander \& Lightner, 2005; Davis \& Arend, 2013; Haskell, 2000; Pintrich, 2002; Salomon \& Perkins, 1989); however, that was not the focus of their research. In contrast, our exploration specifically considers how metacognition might overcome common obstacles to learning transfer and facilitate transfer from one context to the next. Unlike previous work, our investigation includes both staff and student perspectives. We argue metacognition could serve as an effective tool and might support students' learning transfer in at least the following ways:

First, learners should benefit from the awareness that learning transfer is important for success in the university setting, employability, and citizenship, and that successful learning transfer depends on development of transfer skills (strategies and attitudes that support the transfer of learning from one context to another). If students do not realize that being able to transfer learning across contexts is a skill worth cultivating, then they are far less likely to develop it.

Second, metacognition can help students differentiate a variety of contexts in which transfer might occur and encourage them to 'tune in' to how content and skills in their personal repertoire might apply to a current transfer opportunity. Shepherd (2000) suggests that students ask themselves, i.e., bring into their awareness, a series of questions related to the 'Six A's' (analysis, association, assessment, adaption, application, appraisal). Students can pause to consider the essential characteristics of the problem and whether their solution matches the task at hand. They can identify their existing skills and content before considering how to adapt to the new situation. If students decide to use metacognition to guide their transfer learning (see Figure 1a), then they could ask themselves what they know that could apply to the current situation and how that understanding might be adapted. For example, students might develop the realization that knowledge of fluid pressure learned in physics can be used to help understand blood pressure in a nursing course (see Figure $1 \mathrm{~b}$ ). In addition to making connections between content areas, students can learn to transfer skills and procedures. For example, they can come to see that general writing techniques learned in history can be used in literature and chemistry, although they must also recognize the different disciplinary contexts so that they can adapt the detailed aspects of their writing practices.

Third, self-monitoring could help students increase awareness of whether a transfer strategy is appropriate and working well. Students should ask themselves whether they are satisfied with the result. For example, they might ask themselves whether the modifications to their existing knowledge or skills were appropriately adapted to the new transfer opportunity. If not, then they should consider how they might make further modifications. Additionally, students should reflect on why learning transfer did or did not occur (e.g., lack of time, unable to find connections, sense that it was unnecessary), and when another strategy for facilitating transfer might be called for. These types of reflection align with the last of the 'Six A's,' namely 'appraisal' (Shepherd, 2000). Self-monitoring can support learning transfer because it helps students realize when, where, and how particular transfer strategies are effective.

Fourth, also indicated in Figure $1 \mathrm{a}$ and $1 \mathrm{~b}$, self-regulation is ultimately required because it refers to the behaviors that follow from the awareness moments identified in the above three points. For example, if self-monitoring has revealed a particular skill or use of content is ineffective in a particular 
context even though it was effective in a prior context, then students must learn to intentionally choose to engage in an alternative strategy.

Figure 1a. Schematic of how the use of metacognition can enhance learning transfer by encouraging thoughtful choice of content and skills from the personal repertoire

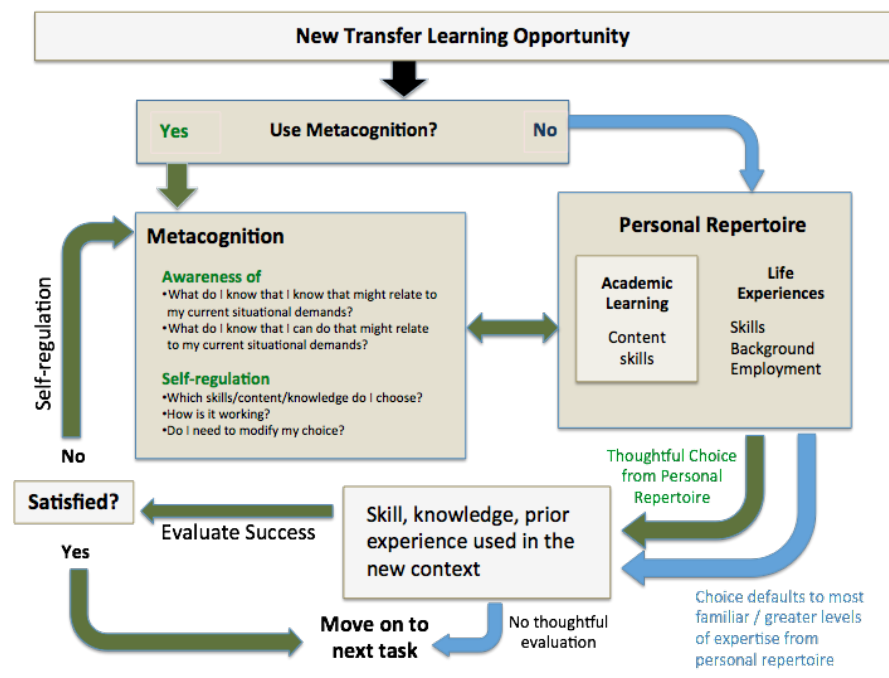

Figure 1b. Illustrates how a new situation (the need to understand blood pressure) might initiate transfer. Metacognition can encourage use of less familiar (smaller font) but more pertinent knowledge rather than simple defaulting to that which is most familiar (larger / bold font).

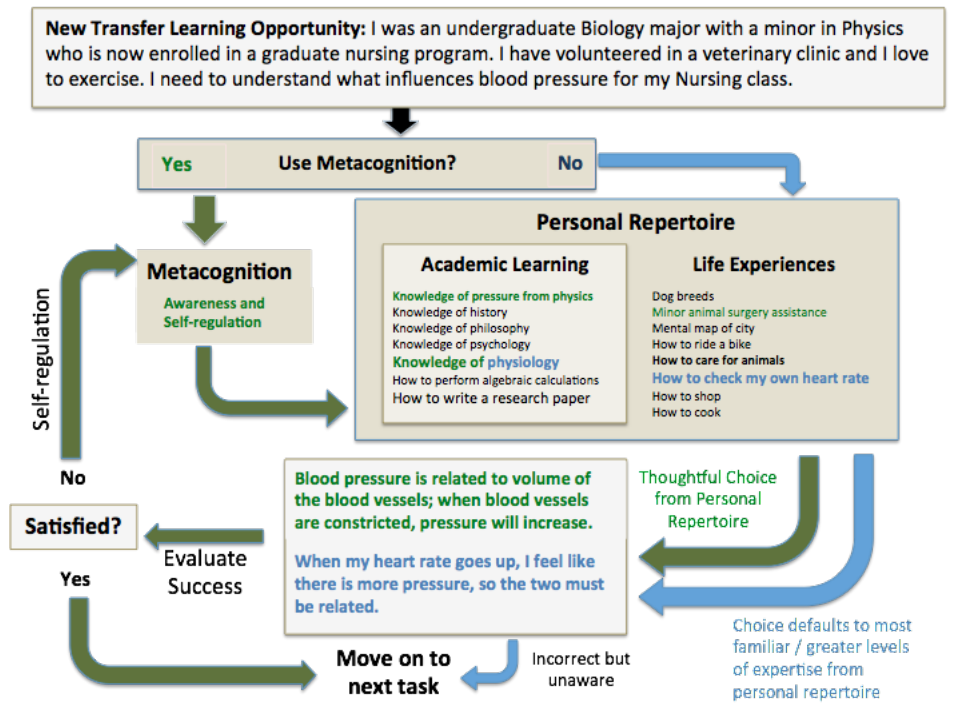

Known challenges to the incorporation of metacognition

Although metacognition seems promising as an approach for supporting learning transfer, prior research on the use of metacognition in support of other learning processes has revealed that metacognition is difficult to develop and implement within a course, much less across courses or other contexts. From an instructor's perspective within a course, an emphasis on metacognition can be perceived as outside their area of subject expertise compared to the usual way of delivering content (O’Connor, 2006). Additionally, despite the long-term advantages of working on transfer and 
metacognition during formal class time, dealing with these topics might be perceived by educators as consuming the time available to 'cover the material.' Beyond an individual course, metacognitive efforts might be different from what higher education institutions - and the individuals themselves - usually pay attention to and value. Further, developing transfer skills requires a wide range of contexts in which students can explore and practice transfer. Thus, to truly support the development of transfer skills and lifelong learning, staff across a program or curriculum need to work together to support metacognitive practices and provide broadening opportunities for transfer.

Another challenge is that while staff may have good intentions, if they lack understanding of learning and transfer processes and do not practice metacognition within their own realm, then their ability to develop such skills in their students may be compromised. Traditionally, instructors develop expertise in their discipline, but receive little formal training in teaching and learning. Over time, many instructors intuitively develop understanding of student learning; however, putting some effort into becoming familiar with formal theories of learning (e.g., Bloom's taxonomies, Kolb's Learning Cycle) might speed that developmental process and give instructors greater insight into how and why some students struggle and how to help them.

On the learner's side, challenges include that students often do not perceive the benefit of metacognition (Larmar \& Lodge, 2014), they view metacognitive exercises as irrelevant to their studies, and they prefer to take a more passive approach to their learning (Paris \& Paris, 2001). Students, therefore, do not engage in metacognition, and often regard it as an 'add-on' rather than an integrated part of their life-long learning. Further, because students may not value deep learning, they adopt a surface approach focusing on short-term learning and memorizing of facts to achieve a grade (Biggs, 1988).

\section{EXPLORATORY INVESTIGATION: PILOT SURVEY OF PERCEPTIONS ON METACOGNITION AND LEARNING TRANSFER}

We argue above that metacognition could serve as a way to support learning transfer and the development of transfer strategies. We also propose possible challenges, some of which might lead to different perceptions of the need for and value of metacognition and transfer skills by students and instructors. To explore our suppositions, we conducted an exploratory pilot survey framed around two broad research questions:

1. What are students and staff perceptions of learning transfer and metacognition?

2. How do these perceptions compare between students and staff, and by level of experience as a learner or teacher?

More specific sub-questions guided our investigation and data analysis, and provided a framework to present our findings:

1. What do students and staff think 'transfer of learning' means and why might it be important?

2. How often do students and staff explicitly think about engaging in or supporting student engagement in applying learning to new contexts, and does that depend on whether that application is similar or less similar?

3. What factors deter engagement in or support transfer of learning?

4. What approaches are used to promote learning transfer?

5. How aware are students and instructors of learning processes, and do they use that awareness to select study strategies?

6. Does greater formal knowledge of learning processes lead to enhanced metacognitive practices or greater effort toward learning transfer? 
Responses helped us form suggestions for future efforts to use metacognition to support transfer, to inform SoTL practitioners, and to identify directions for further SoTL inquiry.

\section{Methods}

Our self-developed survey was approved by the ethics boards at each institution for online dissemination. Staff and student versions were very similar, with 16 and 15 metacognition and transferrelated questions, respectively, plus demographics questions. The majority were closed-ended Likertscale questions, with a few open-ended questions. Because the survey was disseminated internationally, we clearly informed respondents at the beginning of the survey that reference to 'instructor' in the questions should be considered analogous with 'faculty member, professor, tutor, lecturer, or teacher.' See Appendices 1 and 2 for the full questionnaires. Potential participants were sent an email with a short explanation, a clear statement of the voluntary nature of the survey, and a link.

We collected pilot survey data from a convenience sample of 74 staff and 118 students at the following institutions: University of Queensland, Australia (6, 18, respectively); University of Liege, Belgium (7, 7); Leeds Beckett University, UK $(24,0)$; Newcastle University, UK $(8,27)$, and SUNY Buffalo State, USA $(24,47)$. Respondents in both groups were categorized based on level of experience: new, mid, or advanced (see Table 1).

Table 1. Level of experience categorizations and NS for each group

\begin{tabular}{l|l|l|c}
\hline LEVEL OF EXPERIENCE & OPERATIONAL DEFINITION & \# STUDENTS & \# STAFF \\
\hline New & $\begin{array}{l}1^{\text {st }} \text { year undergrad students; } \\
\text { 0-4 years of teaching if staff }\end{array}$ & 20 & 9 \\
\hline Mid & $\begin{array}{l}\text { All other undergraduate students; } \\
5-10 \text { years of teaching if staff }\end{array}$ & 50 & 34 \\
\hline Advanced & $\begin{array}{l}\text { Graduate students; } \\
16+\text { years of teaching if staff }\end{array}$ & 29 & 26 \\
\hline
\end{tabular}

\section{Results and discussion}

Below we briefly summarize and discuss our data to address each of the six guiding questions we shared above. For each, we will compare responses from students and instructors, and report whether or not level of experience seems to influence the responses. Given the small sample size, we combined data from all institutions for our analyses, which also serves to reduce institution-specific effects.

\section{Guiding question 1: The meaning of transfer and its importance}

Across all experience levels both students and instructors in our survey had difficulty describing learning transfer, with $2 / 3$ of student respondents struggling to define learning transfer (see Figure 2). Definitions were imprecise and the themes of the responses were contradictory. Students often referred to learning transfer as an emergent, organic, subconscious, 'natural process.' This subconscious type of process is indicated in Figure 1 by the path not involving metacognition; sometimes the default, more familiar, content or skill might work to support transfer, but in other cases, it may fail. Some staff also reported learning transfer was not always a conscious process for their students; however, others reported learning transfer requires active engagement, which suggests more awareness. These findings 
align with Salomon and Perkins (1989), who noted that learning transfer is a notion that easily escapes attention and is not often explicitly discussed or clearly characterized.

\section{Figure 2. Categorization of staff and students' open-ended definitions of learning transfer}

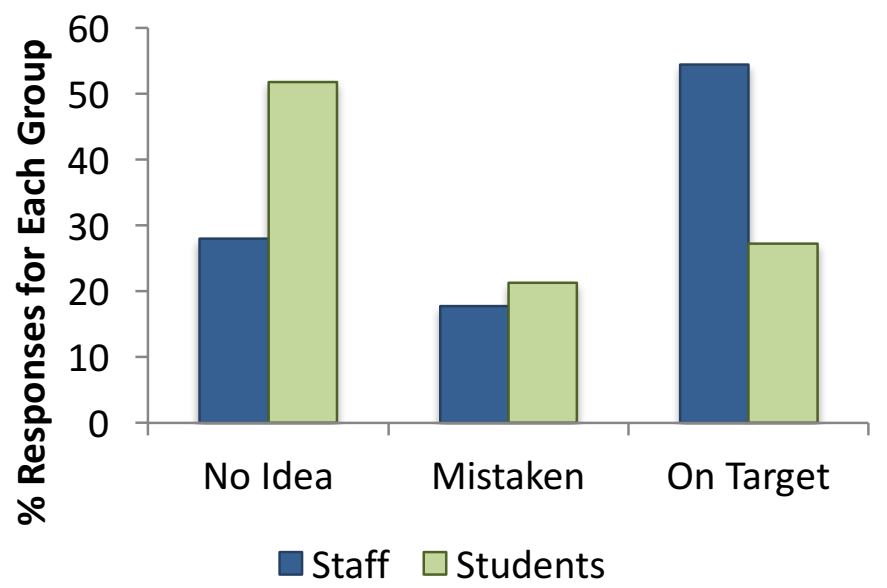

While both staff and students had difficulty precisely defining learning transfer, both groups referred to the positive role of learning transfer in employability, gaining new perspectives, and independent problem solving. However, students and staff placed different emphasis on these skills. Students, for example, reported that learning transfer gives them skills to cope with imminent graduate employment in their field. Staff, in contrast, reported that a student's ability to engage in learning transfer facilitates reflective thinking and promotes deeper insight.

Also related to perceived importance, staff were significantly more likely to agree $(M=1.6$, with $1=$ strongly agree and $6=$ strongly disagree) with the statement that they help students recognize the importance of transferring their learning from the current class to other academic or non-academic contexts than students agreed with the statement that their instructors help them do so, $(\mathrm{M}=2.53)$; $F(1,173)=25.93 ; p<.01$.

Perhaps the lack of clear understanding about learning transfer underlies the disconnect between staff and student perceptions about its importance and whether that importance is clearly communicated. However, based on personal observations, this type of disconnect between staff and student perceptions is common across many topics and suggests staff are not as explicit in their communications as they think they are. In fact, making expectations about transfer explicit is the first recommendation for teaching transfer listed in Benander and Lightner (2005).

Guiding question 2: Frequency of thinking about, engaging in, or supporting learning transfer

Additional mismatches between students and staff were revealed in their behaviors related to transfer. Staff, regardless of level of experience, reported explicitly thinking about helping students apply their learning from one context to another significantly more often than students explicitly think about doing so themselves $F(1,174)=8.53, p<.01(\mathrm{M}=4.03$ and 3.57 , respectively, with $1=$ never and $5=$ every day). There was a non-significant trend, $F(2,96)=2.34, p=.10$, that students think more about transfer as they become more advanced in their courses. Finally, our data also revealed clear mismatches regarding how often staff expect students to apply their learning from one context to another. Regardless of level of experience, staff report expecting students to engage in transfer more often, on average nearly 
'every week' $(M=3.9)$, while students reported perceived expectations closer to 'sometimes during the semester' $(M=3.4), F(1,168)=9.44, p<.01$.

These findings provide further support for the conclusion that staff and students should be more explicit in their communication about learning, transfer, and expectations, and the conclusion that perhaps there are some developmental shifts, with more advanced students showing greater awareness of and attempts at applying transfer beyond the classroom, and with staff showing more than students.

Guiding question 3: Deterrents to transfer

Learning transfer requires applying learning from one context to new, often different, learning contexts. Figure 3 shows the percentage of students and staff identifying various deterrents for students engaging in transfer, with each group normalized by their total number of responses (they were given a list and could choose all that applied to them). Both staff and students reported the greatest deterrent for students transferring their learning was the lack of obvious connections between the learning contexts. Limited time and having too much material were also reported fairly highly by both groups. The biggest difference in staff and student perceptions occurred for the statement that students have no interest (believed more strongly by staff) and that the specific instructor did not require it (believed more strongly by students). These latter mismatches again speak to a miscommunication between staff and students. When asked in a separate question, staff reported the top barrier to their promoting transfer within their courses was that there was too much material, followed by lack of time. It is possible these perceptions make it less likely that staff will take class time to discuss learning and transfer.

Figure 3. Percent of staff and students who indicate different barriers to learning transfer

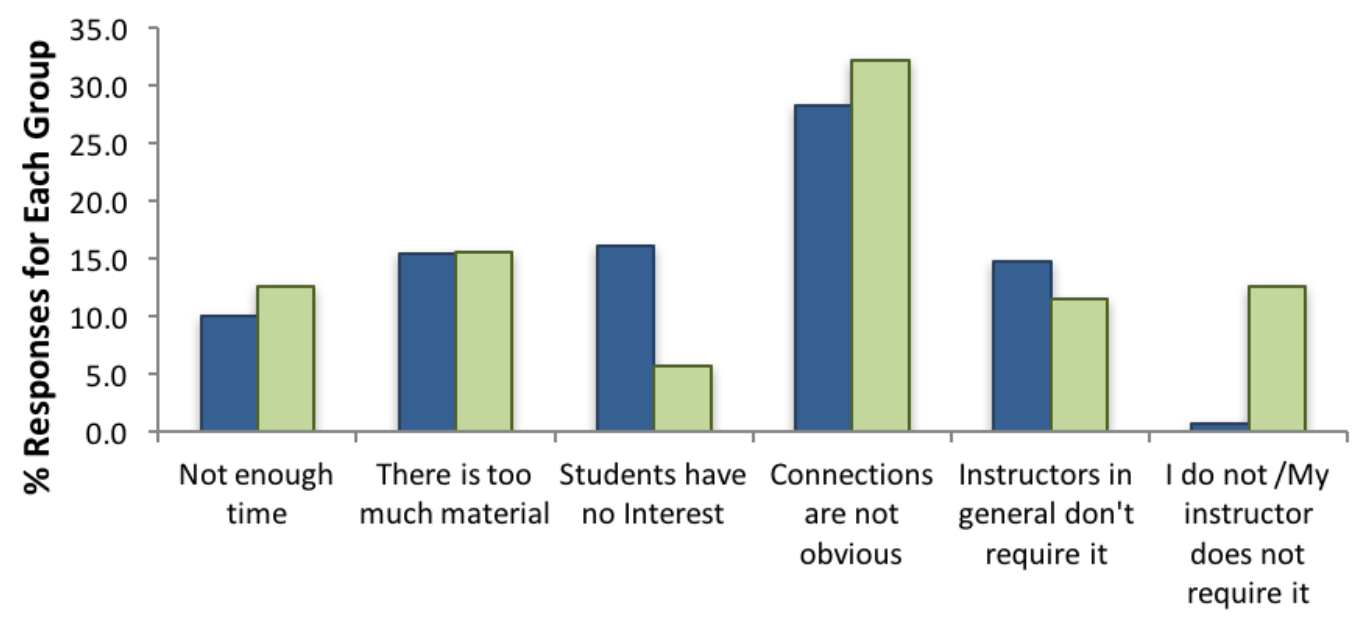

$\square$ Staff $\square$ Students

\section{Guiding question 4: Strategies used to promote transfer}

Intentionally providing opportunities for learning transfer not only requires staff and students to overcome identified barriers, but also requires both to identify evidence-based strategies for learning transfer. When staff were asked about strategies for promoting learning transfer, $56 \%$ offered a variety of general approaches to support transfer. Examples included: "I revisit information acquired in prior required classes to help them see the connection" and "I require them to consider multiple, distinctive, 
practical applications." Eleven percent of staff offered specific pedagogical strategies or tools. Examples included: "I require that student journals and papers explicitly discuss applying the concepts in my course in other classes and/or other areas of their lives" and "Use virtual patient scenarios for safe simulation.” Thirty-three percent of staff offered general strategies for supporting student learning without mentioning learning transfer in particular. Examples included: "Look for analogies from their everyday life to the principles being discussed" and "Using examples from outside the core module material helps students understand the key concepts."

In contrast, students were less likely to offer specific strategies and their responses often highlighted their lack of appreciation for explicit efforts related to engaging in transfer. Examples included the following: "I think that I don't use specific strategies to transfer my learning. However, I use it naturally when the situation occurs;" "It's not something I think about in such a segregated, clear-cut fashion. Learning and applications of it are ingrained into everyday life. To try and define it so coldly seems pointless to me;" and "The only time I'm aware of this happening is when I recognize there's a correlation between different situations. It's 'after the fact' compared to being conscious decision 9 times out of 10." When given a list of strategies that might be used to promote learning transfer (e.g., actively learning, reflective thinking, case studies, concept mapping, quizzes), no one strategy emerged from either staff or students as being more often used than any other in supporting learning transfer.

Responses to the definition question suggested a lack of clear understanding and/or appreciation for learning transfer, although once it was explained, staff and students both reported reasons why it would be valuable. Importantly, however, if one spends little time explicitly thinking about learning transfer, it is unlikely that one would put much intentional effort into developing it as an instructor or notice efforts to develop it as a student. Further, even if an instructor wanted to intentionally promote learning transfer, resources may not be readily available to guide instructors in pedagogical choices. One of the key suggestions in the literature is that instructors should explicitly discuss and highlight transfer (e.g., Benander \& Lightner, 2005). This focus on explicitness leads to awareness, which is one of the foundational aspects of metacognition, and which underpinned three of our four ways by which we proposed metacognition could support transfer.

In contrast to the realm of transfer, there has been much research on pedagogies to support the development of metacognition. For example, Tanner (2012), Wirth and Perkins (2008), Kuiper and Pesult (2003), and Bannert, Sonnenberg, Mengelkamp, and Pieger (2015) all propose several means by which staff can incorporate metacognition, many of which seem directly applicable to supporting learning transfer (e.g., mindfulness activities, active consideration of multiple application contexts, concept mapping, peer discussion, reflective processing, teacher modeling of metacognitive practice and specific metacognitive question prompts, and assessment of prior knowledge via pre-module quizzes). Thus, SoTL efforts in metacognition could focus on providing guidance for staff who desire to promote learning transfer in their courses.

\section{Guiding question 5: Awareness of learning processes and use of that awareness (self- regulation)}

In an effort to explore behaviors that might underlie metacognition, we asked staff and students several questions about their tendencies to think about student learning strategies in general, how often their awareness of choice of learning strategies affected their teaching and learning practices (selfregulation), and their understanding of formal theories of human learning. As with several of the questions above, there were clear mismatches between staff and students. These mismatches further 
support two premises proposed above regarding causes of student and staff differences, 1) non-explicit communication and 2) development / maturation of students.

When asked how often they thought about learning processes in general, staff reported thinking about them significantly more often than did students $F(1,165)=16.12, p<.01(\mathrm{M}=4.24$ and 3.67, respectively, with $1=$ never and $5=$ very frequently). While staff level of experience did not impact thinking about learning processes, there was a trend for students, $F(2,96)=2.47, p=.09$, that as students became more advanced, they thought more about learning processes. On average, staff reported thinking 'regularly' to 'very frequently' about their teaching strategies, with level of experience not affecting this behavior.

When asked how often awareness of the efficacy of learning strategies guided their practice (note the self-regulation component in Figure 1a and $1 \mathrm{~b}$ ), staff were significantly more likely than students to report that their thinking about student learning strategies guided their [teaching] practice, $F(1,168)=18.26, p<.01(\mathrm{M}=4.93$ and 4.21 , respectively, with $1=\mathrm{I}$ never think about it and $6=$ very frequently guides). Level of experience did not affect staff reports, but students reported significantly greater use of awareness as they became more experienced, $F(2,96)=5.69, p=.02$.

When asked about their single primary consideration in discussing learning strategies (staff) or choosing a learning strategy (students), staff more often chose the option 'helping students later in life' as their primary consideration, especially if they were more experienced staff. Students were more likely to choose the option of 'passing the next test;' especially if they were first-year students. See Figures 4 and 5 for a tally of the responses. This pattern suggests there is a developmental trend with newer students largely focused on very near-term performance such as passing the next test, and with some more advanced students shifting their primary consideration to learning for their studies at large and to learning for later life. A strong focus on the next test is not surprising as some of the most salient aspects of school for students, even prior to university, are assessment and grades (e.g., Wyatt, Saunders, \& Zelmer, 2005). In contrast, staff of any experience level rarely chose 'passing the next test' as their primary consideration, but there also seems to be a developmental shift toward lifelong learning with more advanced levels of experience.

Figure 4. Tally of staff responses regarding their primary consideration when talking to their students about how they study for their classes

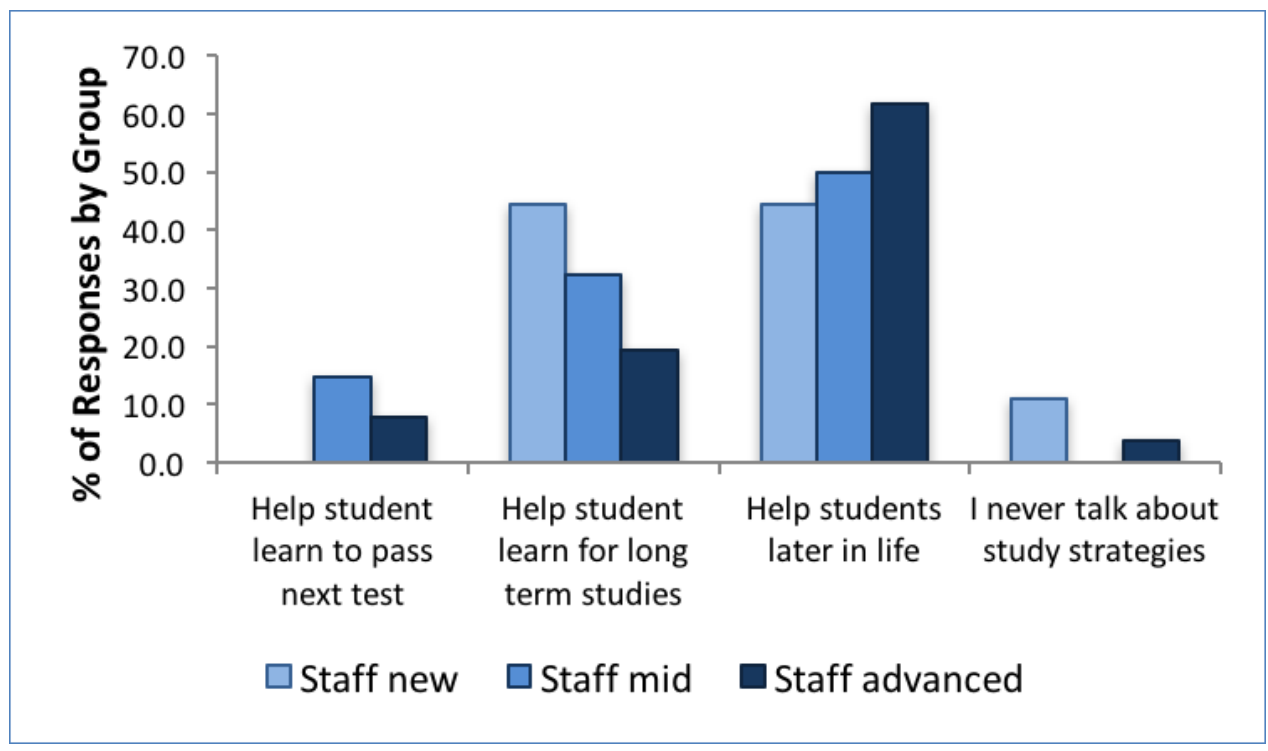


Figure 5. Tally of student responses regarding their primary consideration when choosing a study strategy

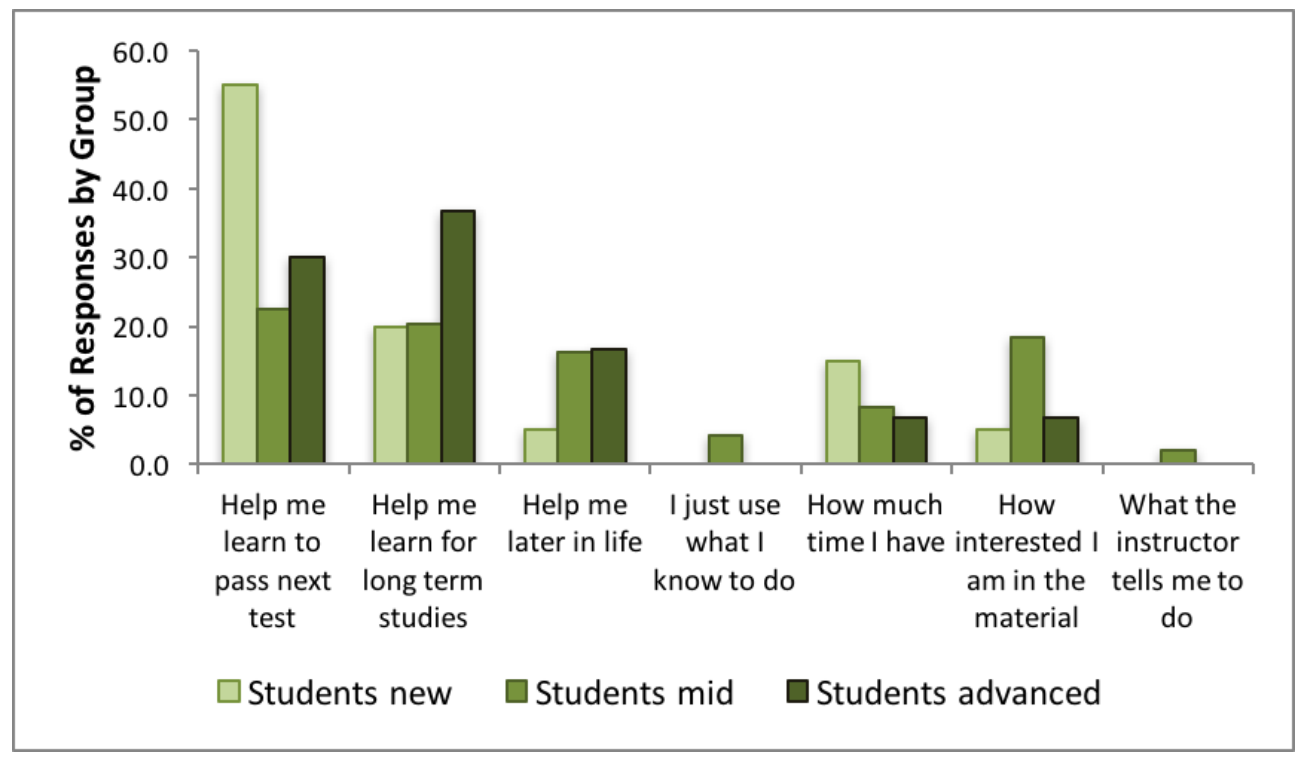

In addition to engaging in general reflection about the learning process, we wondered if more explicit knowledge about formal learning strategies might be related to thinking about transfer. Unsurprisingly, staff reported greater levels of personal familiarity with formal learning theories than did students, $F(1,68)=18.75, p<.01$. Staff, regardless of level of experience, on average rated themselves as closer to having 'fairly good' rather than 'very basic' understanding $(M=2.61)$. Students on average reported having a 'very basic' understanding $(\mathrm{M}=2.1)$, but also showed a significant increase with level of experience, $F(2,96)=3.16, p<.05$, starting with many new students reporting 'no knowledge' of learning theories.

An additional miscommunication was revealed through responses where staff and students rated each other's level of knowledge of formal learning theories. Compared to the self-ratings, staff underestimated students on average $(M=1.59)$, and students overestimated staff level of familiarity $(M$ $=2.84), F(1,165)=109.70, p<.01$. We believe that if staff more explicitly and frequently discussed and integrated learning about learning throughout the duration of the course, then both staff and students would be able to more accurately estimate each other's level of knowledge, as well as increase levels of knowledge about learning processes.

Guiding question 6: Linking metacognition and learning transfer

Because we conducted a survey, we cannot directly test our premise that the use of metacognition might support learning transfer. However, we can determine whether our overall sample (staff and students combined) shows relationships between metacognition-related behaviors and the likelihood to think about transfer. In fact, there are several significant correlations. Thinking more frequently about how to apply learning from one context to another significantly and positively correlates with: the likelihood to think about learning processes in general, $r(165)=.48, p<.01$, the likelihood to think about learning strategies, $r(168)=.46, p<.01$, and teaching strategies $r(66)=.42, p$ $<.01$, the likelihood to use awareness to guide practice, $r(168)=.51, p<.01$, and the likelihood to rate oneself as familiar with formal learning strategies, $r(168)=.33, p<.01$. Interestingly, the strongest 
correlation is between the self-regulation aspect of metacognition (using awareness to guide practice) and thinking about transfer. Overall, we believe that these relationships suggest promise for further inquiry into the use of metacognitive practices to support learning transfer.

\section{CONCLUSIONS AND FUTURE DIRECTIONS}

Our small-scale pilot study illuminates an area rich for future SoTL investigations. The current higher education climate is characterized by increased international competition, growing accreditation demands, and employers who seek graduates who can adapt, learn independently, problem solve creatively, and choose an appropriate solution for a situation they have not encountered before. Thus, in order to support our graduates' employment and lifelong learning, we must ensure that they have the ability to appropriately transfer learning. However, our results indicate many staff and a majority of students do not have a clear understanding of what learning transfer entails, and that there are many mismatches between staff and student perceptions, attitudes, and behaviors regarding learning transfer.

We believe these findings largely result from two factors, 1) lack of explicit communication to promote awareness and shared expectations, and 2) some development / maturation influences evidenced by the differences seen across levels of experience within each group and across groups. If staff and students do not realize learning across contexts is a skill worth cultivating, then they are far less likely to discuss it or take intentional actions to develop it. As with other skills, becoming adept at learning transfer (or becoming effective at teaching learning transfer) will require multiple opportunities for practice coupled with feedback, both of which will not tend to happen spontaneously, but instead require purposeful lesson design by the staff member and effort by the learner.

Unfortunately, the staff, administrators, and other stakeholders in higher education are often not well-versed in the topics of learning processes and effective strategies by which to best enhance learning. Further, given typical institutional structures, there are few opportunities or expectations for collective curriculum planning (Lattuca \& Stark, 2011). Rather, as reinforced by our findings, the pressure to cover content is felt at institutions around the world and frequently dominates lessons in the often-isolated courses within the curriculum. This narrow focus makes it difficult to make the necessary wide range of transfer connections that will best support the development of lifelong learning skills in our students. In fact, our staff and student respondents primarily indicated transfer involved 'application' of knowledge or skills to very similar contexts or job situations, and none explicitly indicated that what might be transferred from many courses are thinking skills or approaches to learning. Thus, there is a real need to shift perspectives of both staff and students if deep learning and effective learning transfer are to be realized.

Our specific suggestions for implementation and future SoTL research include both in-theclassroom efforts as well as broader efforts at institutions:

- Engage in broad conversations about the major trend we observed in our pilot data: that learning transfer is often not clearly understood or explicitly supported in our classrooms.

- Explore ways to increase students' awareness that learning transfer can be a conscious, active process that will be useful to them in their coursework as well as later in life.

- Determine specific, evidence-based strategies staff could easily adopt to help enhance the use of learning transfer, including approaches to use with first-year students.

- Encourage staff development in the realms of teaching and learning, including an understanding of theories of intellectual development so that staff do not assume a single, 'one-size-fits-all' approach will be effective for all their students. 
- More systematically investigate whether a metacognitive approach leads to increased transfer of learning, and how that might be influenced by disciplinary, institutional, and geographical differences.

Changing an institutional environment is difficult. It will require awareness of the issues coupled with explicit communication both among staff and between staff and students of why and how change should occur. It will also require intentionality and self-regulation of behaviors to support new ways of educating and learning. These characteristics of awareness and self-regulation suggest the use of a metacognitive approach to more effectively select from one's personal repertoire of content and skills. Although our sample was relatively small, our data indicate strong correlations between metacognitive behaviors and thinking about learning transfer and suggest metacognition might indeed be a useful approach by which to promote learning transfer and, by extension, employability and lifelong learning.

\section{ACKNOWLEDGEMENTS}

We give special thanks to Marion Tower (University of Queensland) for her thoughtful contributions during the early stages of the project. We also thank ISSoTL's International Collaborative Writing Group Program, led by Kelly Mathews and Mick Healy.

Lauren Scharff is Director, SoTL Program and Professor of Behavioral Sciences at United States Air Force Academy.

John Draeger is Director of SoTL and Associate Professor of Philosophy at SUNY Buffalo State.

Dominique Verpoorten is Lecturer of Learning Sciences at IFRES-University of Liège.

Marie Devlin is Lecturer of Computing Science at Newcastle University.

Lucie S. Dvorakova is an Honors Student at the Institute for Molecular Bioscience, University of Queensland.

Jason M. Lodge is Senior Lecturer at the Melbourne Centre for the Study of Higher Education, University of Melbourne.

Susan Smith is Head of Curriculum Development and Review at Leeds Beckett University.

\section{REFERENCES}

Bannert, M., Sonnenberg, C, Mengelkamp, C., \& Pieger, E. (2015). Short-and long-term effects of students' selfdirected metacognitive prompts on navigation behavior and learning performance, Computers in Human Behaviour, 52, 293-306.

Benander, R., \& Lightner, R. (2005). Promoting transfer of learning: Connecting general education courses. The Journal of General Education, 54(3), 199-208.

Biggs, J. (1988). The role of metacognition in enhancing learning, Australian Journal of Education, 32 (2), 127-138.

Billing, D. (2007). Teaching for transfer of core/key skills in higher education: Cognitive skills. Higher Education, 53 (4), 483-516.

Case, J., \& Gunstone, R. (2002). Metacognitive development as a shift in approach to learning: An in-depth study. Studies in Higher Education. 27(4), 459-470.

Chick, N. L., Karis, T., \& Kernahan, C. (2009). Learning from their own learning: How metacognitive and metaaffective reflections enhance learning in race-related courses. International Journal for the Scholarship of Teaching and Learning, 3(1), 16.

Cronon, W. (1998). "Only connect..." The goals of a liberal education. The American Scholar, 6(4), 73-81.

Davis, J., \& Arend, B. (2013). Facilitating seven ways of learning: A resource for more purposeful, effective and enjoyable college teaching. Sterling, Virginia: Stylus Press. 
Douglass, C., \& Morris, S. R. (2014). Student perspectives on self-directed learning. Journal of Scholarship of Teaching and Learning, 14(1), 13-25.

Haskell, R. (2000). Transfer of learning: Cognition and instruction. New York: Academic Press.

Higgins, S., Wall, K., Baumfield, V., Hall, E., Leat, D., Moseley, D., \& Woolner, P. (2007). Learning to Learn in Schools Phase 3 Evaluation.

Hoskins, B., \& Fredriksson, U. (2008). Learning to Learn: What is it and can it be measured? (JRC Scientific and Technical Report EUR 23432 EN). Brussels: European Commission, Joint Research Centre.

Huber, M. T., \& Hutchings, P. (2004). Integrative learning: Mapping the terrain. The Academy in Transition. Association of American Colleges and Universities.

Isaacson, R., \& Fujita, F. (2006). Metacognitive knowledge monitoring and self-regulated learning: Academic success and reflections on learning. Journal of the Scholarship of Teaching and Learning, 6(1), 39-55.

Kuiper, R., \& Pesut, D. (2003). Promoting cognitive and metacognitive reflective reasoning skills in nursing practice: Self-regulated nursing theory. Journal of Advanced Nursing, 45(4), 381-391.

Larmar, S., \& Lodge, J. (2014). Making sense of how I learn: Metacognitive capital and the first year university student, The International Journal of the First Year in Higher Education, 5 (1): 93-105.

Lightner, R., Benander, R., \& Kramer, E. (2008). Faculty and student attitudes about transfer of learning. Insight: $A$ Journal of Scholarly Teaching, 3, 58-66.

Lattuca, L., \& Stark, J. (2011). Shaping the college curriculum: Academic plans in context. John Wiley \& Sons.

Moon, J. (2001). Reflection in higher education learning. York: Higher Education Academy. LTSN Generic Centre.

Muhamad, S. (2012). Graduate employability and transferable skills: A review. Advances in Natural and Applied Sciences, 6(6), 882-885.

Newman, D., Catavero, C., \& Wright, L. (2012). Students fail to transfer knowledge of chromosome structure to topics pertaining to cell division. CBE-Life Sciences Education, 11(4), 425-436.

Nowacek, R. S. (2011). Agents of integration: Understanding transfer as a rhetorical act. SIU Press.

O'Connor, T. (2006). Different approaches to integrate learning skills development in higher education. Paper presented at the All Ireland Society for higher education conference, Maynooth, Ireland.

Paris, S., \& Paris, A. (2001). Classroom applications of research on self-regulated learning. Educational Psychologist, 36(2), 89-101.

Pintrich, P. (2002). The role of metacognitive knowledge in learning, teaching, and assessing. Theory into Practice, 41(4), 219-225.

Salomon, G., \& Perkins, D. (1989). Rocky roads to transfer: Rethinking mechanisms of a neglected phenomenon. Educational Psychologist, 24(2), 113-142.

Shepherd, I. (2000). Key Skills: Teaching and learning for transfer. Cheltenham: Geography Discipline, Network, Cheltenham and Gloucester College of Higher Education.

Tanner, K. (2012). Promoting student metacognition. CBE-Life Sciences Education, 11(2), 113-120.

Veenman, M., \& Beishuizen, J. (2004). Intellectual and metacognitive skills of novices while studying texts under conditions of text difficulty and time constraint. Learning and Instruction, 14, 621-640.

Watkins, C. (2001). Learning about learning enhances performance. London: Institute of Education, University of London.

Wirth, K., \& Perkins, D. (2008). Learning to Learn.

Wyatt, G., Saunders, D., \& Zelmer, D. (2005). Academic preparation, effort and success: A comparison of student and faculty perceptions. Educational Research Quarterly, 29(2), 29-36. 